\title{
A critical systematic review and synopsis of the alignment of scientific developments in surveillance technology in nursing care facilities
}

Patrick Fehling* and Theo Dassen

*Correspondence: patrick.fehling@charite.de

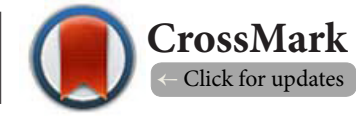

Institute of Health and Nursing Science of the Charité University Medicine, Berlin.

\begin{abstract}
Background: The deficits in the self-care of older people are often associated with a loss of autonomy and if care is not provided in the home environment by relatives or professional caregivers, then the self-care deficits may result in the admission to a residential care facility (RCF). On the other hand, in industrialized countries, the recruitment and long-term retention of professional caregivers are becoming increasingly difficult. Technical aids such as sensor technology (SeTe) could solve this dilemma and improve the autonomy, the quality of life, and the safety of the residents.
\end{abstract}

Objectives: To analyze the nursing problems targeted in the studies, where was the SeTe used, and why has it been chosen, the technical limitations of SeTe and whether the studies contain ethical considerations.

Design: This review followed the Cochrane Collaboration methods for systematic reviewing. The databases EBSCOhost (which includes CINAHL, MEDLINE, and PsycINFO), Web of Science, Cochrane Library, and Google Scholar were searched.

Methods: This critical systematic review analyzes publications on SeTe if the nursing problems referred to by scientists have been in connection with residents of RCFs. Studies that focused on participants in hospitals and home environments or those using gaming consoles or medical applications were excluded.

Results: Of the 49 studies included, 31\% used only accelerometers, $20 \%$ used cameras, and 29\% combined various types of SeTe devices. The use of various SeTe was beneficial, possibly because the more perspective data are combined. $51 \%$ preferred non-wearable SeTe devices, $2 / 3$ preferred the permanent surveillance by SeTe devices. The nursing problems which the research teams concentrated on were fall risk, immobility, agitation and sleep problems. Only $1 / 4$ of the studies mention current or potential ethical considerations regarding the surveillance of residents by SeTe devices.

Conclusion: It is gratifying that the international interest in researching SeTe in RCFs has increased. Ethical dilemmas were hardly discussed. The future use of SeTe in RCFs is certainly desirable and unavoidable, but consulting the residents, professional caregivers, and nursing scientists about their requirements for useful and necessary technical surveillance first seems usefull.

Relevance to Clinical Practice: Currently RCFs should continue to use the SeTe cautiously. Professional caregivers in RCFs should be able to convey the growing self-image of nursing into similar SeTe research projects.

Keywords: Accelerometer, camera, nursing home residents, nursing problems, surveillance technology, review

\section{Introduction}

Throughout the world, there are technological developments in private and professional everyday life. These developments also pervade the health and care sectors. Whereas most technical achievements have already been established in the medical field, the nursing profession is rather cautious about the use 
Fehling et al. Journal of Nursing 2017,

http://www.hoajonline.com/journals/pdf/2056-9157-4-1.pdf

doi: $10.7243 / 2056-9157-4-1$

of technical assistance, especially for long-term care. During the past few years, however, some researchers have begun to look into technology supporting the surveillance of care recipients. This surveillance technology has been intended to increase the safety of care recipients, also in the long-term, and to provide some relief to the caregivers. The purpose of this review is to examine the state of the art in scientific projects on surveillance technology in residential care facilities (RCFs).

\section{Background}

The deficits in the self-care of older people are often associated with a loss of autonomy, and this is often caused by dementia, multiple falls, or incontinence [1]. Those often affected need support from others; sometimes they need permanent care from caregivers. If care is not provided in the home environment by relatives or professional caregivers, then the self-care deficits may result in the admission to an RCF (ibid.).

In industrialized countries, the number of older adults with self-care deficits is increasing, which means that a growing number needs support by caregivers. The prevalence of people with dementia, for instance, increases exponentially, doubling every 20 years [2]. As a result, a growing number of the RCF residents have problems with cognitive functions [3].

On the other hand, in industrialized countries, the recruitment and long-term retention of professional caregivers are becoming increasingly difficult [4]. Also, RCF caregivers experience a considerable degree of physical, psychological, and emotional stress, especially in the treatment of residents with dementia [2]. This represents an additional hurdle for caregivers working in RCFs $[\mathbf{5}, \mathbf{6}]$. Therefore, it is becoming increasingly difficult for professional caregivers alone to provide quality care for the growing number of residents in the RCFs. Technical aids could solve this dilemma and improve the autonomy, the quality of life, and the safety of the residents [3].

A technical aid that has been researched increasingly in multiple professional fields is sensor technology, such as the sensor-based activity monitoring and fall-and-wandering detection. Devices such as accelerometers, heat sensors, pressure sensors, moisture sensors, tracking devices, and (IR) cameras are already being used. In this review, such surveillance sensor devices are subsumed under the term sensor technology (SeTe). Sensors such as these have been developed to inform residents and caregivers of critical events [7] and to aid nursing in more specific ways [8]. This review attempts to answer the question of which types of SeTe devices have been scientifically investigated in RCFs in recent years. What are the nursing problems that the scientists have focused on?

Ethical conflicts could accompany the increasing use of SeTe devices in RCFs [9]. These conflicts might have a direct influence on the acceptance of SeTe in RCFs, which is a "critical factor for the success of such systems" [2]. Peek et al. [9] describe that many SeTe devices cannot be deactivated, and thus, the privacy of care recipients is in permanent violation. This critical systematic review, therefore, also examines whether the scientists in their studies also take into account the privacy of their participants. And did these scientists also address the ethical concerns of the professional caregivers? In any case, caregivers also have an effect on the use of SeTe in RCFs. Statements like "I could lose my job" [10] portray the fear of caregivers toward being replaceable.

In addition to analyzing the quality of the studies investigated, a synopsis of the studies was created as follows:

- the objectives and the nursing problems targeted in the studies;

- $\quad$ where was the SeTe used, and why has it been chosen;

- the technical limitations of SeTe;

- why SeTe has been tested in RCFs;

- whether the studies contain ethical considerations such as the protection of privacy or the acceptance of SeTe by all stakeholders.

Accordingly, a presentation of the results of the individual studies included in this review was not an objective of this critical assessment and the synopsis.

\section{Method}

Design

This review followed the Cochrane Collaboration methods for systematic reviewing [11] based on the PRISMA principles, the Preferred Reporting Items for Systematic reviews, and Meta Analyses [12].

\section{Data collection}

As the first step, the search engine PubMed was used to screen for studies on "nursing homes" and "sensors". The analysis of abstracts and full texts resulted in common keywords. A second database analysis supplemented these keywords with additional keywords. Third, on the basis of these keywords, the following string search was performed: ("nursing home*" OR "residential care") AND ("surveillance technology" OR "electronic observation" OR "activity monitor" OR tracking OR sensors OR sensor OR "motion detection" OR infrared OR camera* OR accelerometer). The databases EBSCOhost (which includes CINAHL, MEDLINE, and PsycINFO), Web of Science, Cochrane Library, and Google Scholar were searched using this search string on August 3rd, 2016. For these databases, various small adjustments were made in the string without changing the keywords.

The review only included English studies covering the past ten years. On the one hand, there has been a great deal of progress in the development of SeTe, and only the latest developments should be reflected. On the other hand, both de Bruin et al. and Tapo published similar reviews that included studies until January/February 2007 [3,13]. The current review should build on these.

This critical systematic review analyzes publications on SeTe, regardless of the study design or the scientific field in which they were conducted. However, the nursing problems referred to by scientists must have been in connection with 
residents of RCFs. These inclusion criteria necessarily exclude other studies. Studies that focused on participants in hospitals, home environments (Ambient Assisted Living), or those not involving RCFs were excluded. The exclusion criteria were supplemented by:

- Studies which only recommend using their SeTe in RCFs;

- Studies with only healthy/young participants. (Studies supplemented by a healthy control group were accepted);

- Non-electrical/non-electronic sensors;

- Motion sensors integrated into gaming consoles (Xbox, Nintendo), tablet computers, or robots;

- Motion sensors used only for switching lights on or off;

- Smoke and heat detectors used to alert the fire and rescue services;

- Medical applications such as for telemedicine, diagnosing diseases, and measuring blood pressure or body temperature;

- Qualitative studies, as these are to be investigated in a forthcoming review;

- Studies where full texts were not available. If full texts were not available online, authors were asked directly for authorizing access. If these requests were not answered by October 2016, the paper was excluded.

The PRISMA-adapted flowchart of the identification, screening, eligibility, selection, and inclusion process is summarized in Figure 1.

\section{Data analysis}

Each study included was analyzed according to predefined criteria as follows:

- Study characteristics (study design, country of origin, duration of study, number of RCFs as well as the number, age, and diagnoses of the participants involved);

- The objectives of the studies;

- The nursing problem focused on, its definition, and their causes and consequences;

- The reason why the researchers chose the residents of RCFs as a target group;

- Which type of SeTe was applied and why;

- How many SeTe devices were used and whether different types of SeTe devices were used;

- The parameters that apply to SeTe devices, who is the manufacturer or whether a prototype was used;

- Whether the SeTe device is wearable or not;

- Whether the SeTe device was used continuously or only temporarily, such as for a diagnosis;

- Technical problems with the use of any SeTe device;

- Ethical considerations for the autonomy and the privacy of the participants and the acceptance of the SeTe concerned by the target groups.

The data analysis and data synthesis were performed first by the author and were then regularly discussed with the second author and the research team of the Institute. Various interpretations were discussed until a consensus was achieved.
Due to the variety of study concepts incorporated into this review, the study quality assessment tool had to cover such diversity. The Cochrane Handbook proposes a commonly used quality assessment tool that covers the diversity of several quantitative study designs developed by the Effective Public Health Practice Project (EPHPP). “This tool includes components of intervention integrity and was judged to be suitable to use in systematic reviews" [14].

\section{Results \\ Search results}

Out of 541 database results (Figure 1), 49 studies passed the PRISMA flowchart screening, eligibility, and selection (Table 1).

\section{Characteristics of included studies}

The 49 analyzed studies originated from Europe (22x), from Asia (9x) and America, more precisely from the USA, Mexico and Canada (18x). Three studies were conducted in Colombia and Pittsburgh, Leuven (Belgium), Limoges (France) and Maastricht (NL) were represented twice.

The number of included studies on SeTe in RCFs has doubled in the past five years. The major part of the study designs was prospective observational studies, only $14 \%$ was retrospective. This design was mainly used for video analysis of participants.

The quality of the 49 studies is listed in Table 2. Randomization and blinding of the samples were almost never performed. The duration of the 49 studies ranged from a few minutes to several years, on average 280 days. If the partial extensive retrospective studies are subtracted, the average duration of the study was 156 days $=5.2$ months. The recent studies show a slightly longer duration than the older ones.

\section{Characteristics of participants}

Table 1 lists the number of participants and the RCFs where there were 42.8 participants on average. One-third of the samples consisted of ten or fewer participants. Of the studies, $3 / 4$ recruited their participants from one RCF, $11 \%$ from two, and $6 \%$ from three RCFs. The number of RCFs and participants involved has increased over the past ten years. While the studies from the first five years on average included 28.1 participants from 1.43 RCFs, the studies of the past five years included 39.6 participants from 2.0 RCFs (the unusually comprehensive study of Koczy et al. [15] is not included here).

Of the 49 research teams, 28 pragmatically argued why they were mostly testing the SeTe in RCFs and not in hospitals or home environments. Eighteen of them mentioned that the nursing problems that they were interested in, such as falls, restraints, or dementia, often occur in RCFs. As the reason for conducting their research there, three of the studies cited an increasing demand for SeTe in RCFs. Structural reasons for the choice of an RCF, for example, that nurses' "availability is also limited" [16], were hardly mentioned.

In this critical systematic review, 36 studies mentioned the age of their participants (Table 1). On average, the par- 


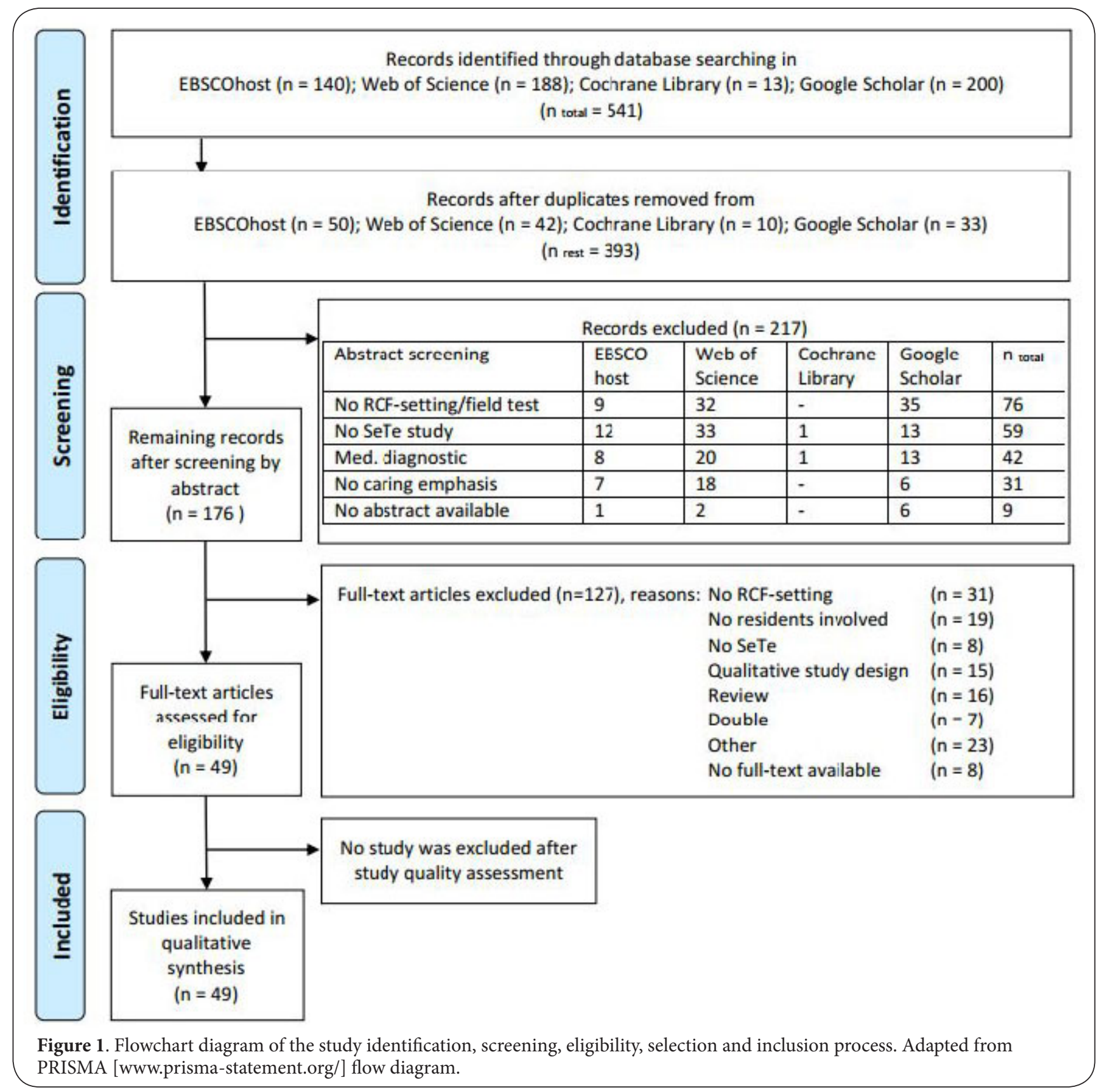

ticipants were 83.03 years old $\left(\sigma^{2}=18.5\right)$ and with a range of 70 to 91 years. However, the studies with participants of an average age of fewer than 83.03 years had almost four times as many participants. Thus, very old residents are underrepresented in the included studies. Thirty-four studies described the medical diagnoses of their participants, mostly as criteria for the participants' inclusion or exclusion. A total of 44 inclusion criteria and 29 exclusion criteria were described. The redundant criteria are listed in Table 3.

\section{Nursing problems researched}

The 57 current or potential nursing problems which the re- search teams concentrated on are shown in Figure 2. Only nine studies have added a definition of their particular nursing problem. Of the authors, $61 \%$ reported a total of 39 causes for the resulting nursing problems. The dementia of the participants $(5 x)$, the nursing staff shortage (4x), or the knowledge deficit of caregivers ( $3 \mathrm{x}$ ) were repeatedly mentioned. The most common argument for the cause of nursing problems in RCFs, however, was the aging of society in industrialized countries (11x).

\section{The Types of SeTe used}

Of the studies included, $31 \%$ used only accelerometers, $20 \%$ used cameras, $10 \%$ used pressure sensors, and $29 \%$ com- 
Fehling et al. Journal of Nursing 2017,

http://www.hoajonline.com/journals/pdf/2056-9157-4-1.pdf

doi: 10.7243/2056-9157-4-1

Table 1. Synthesis of the studies included.

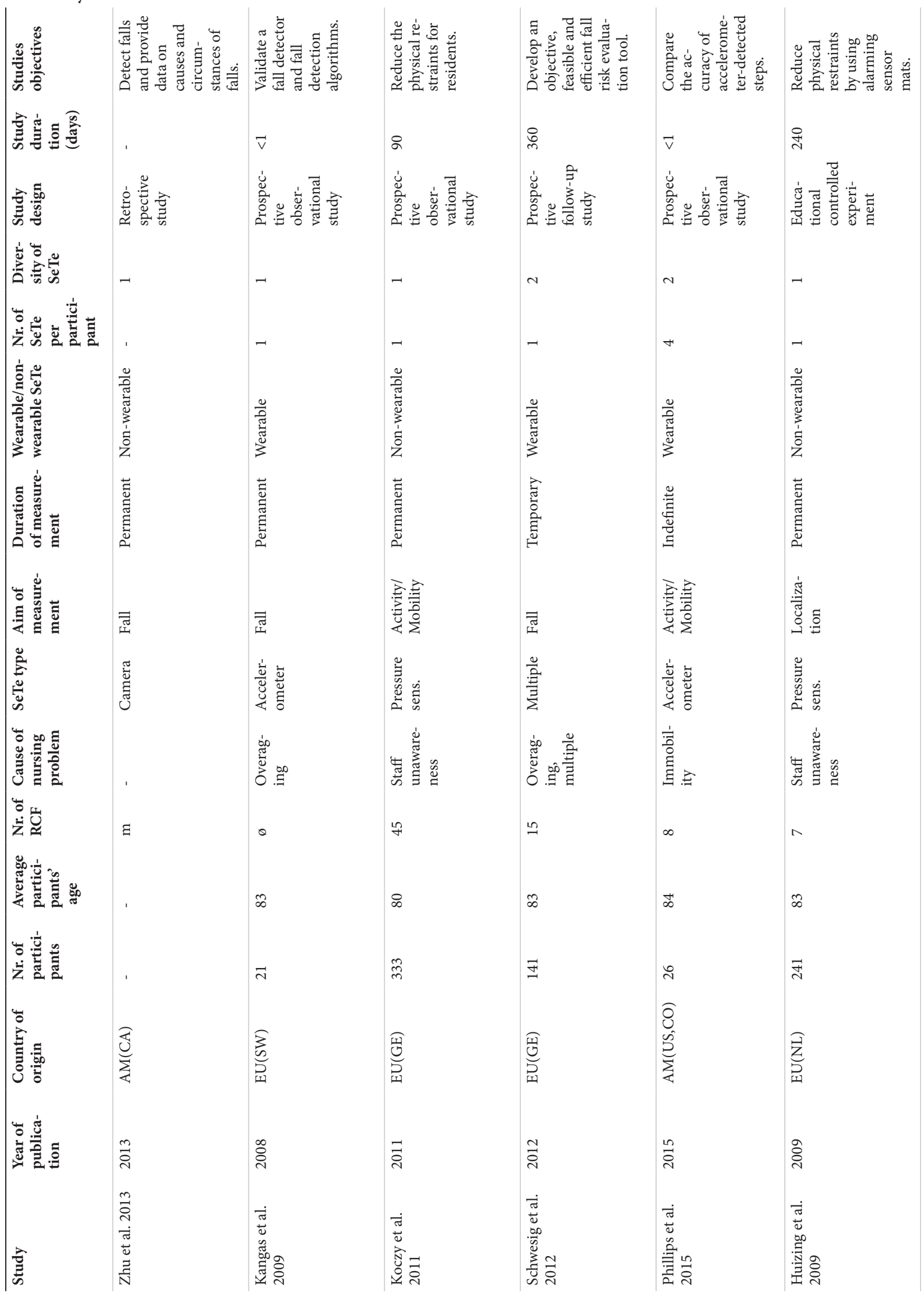




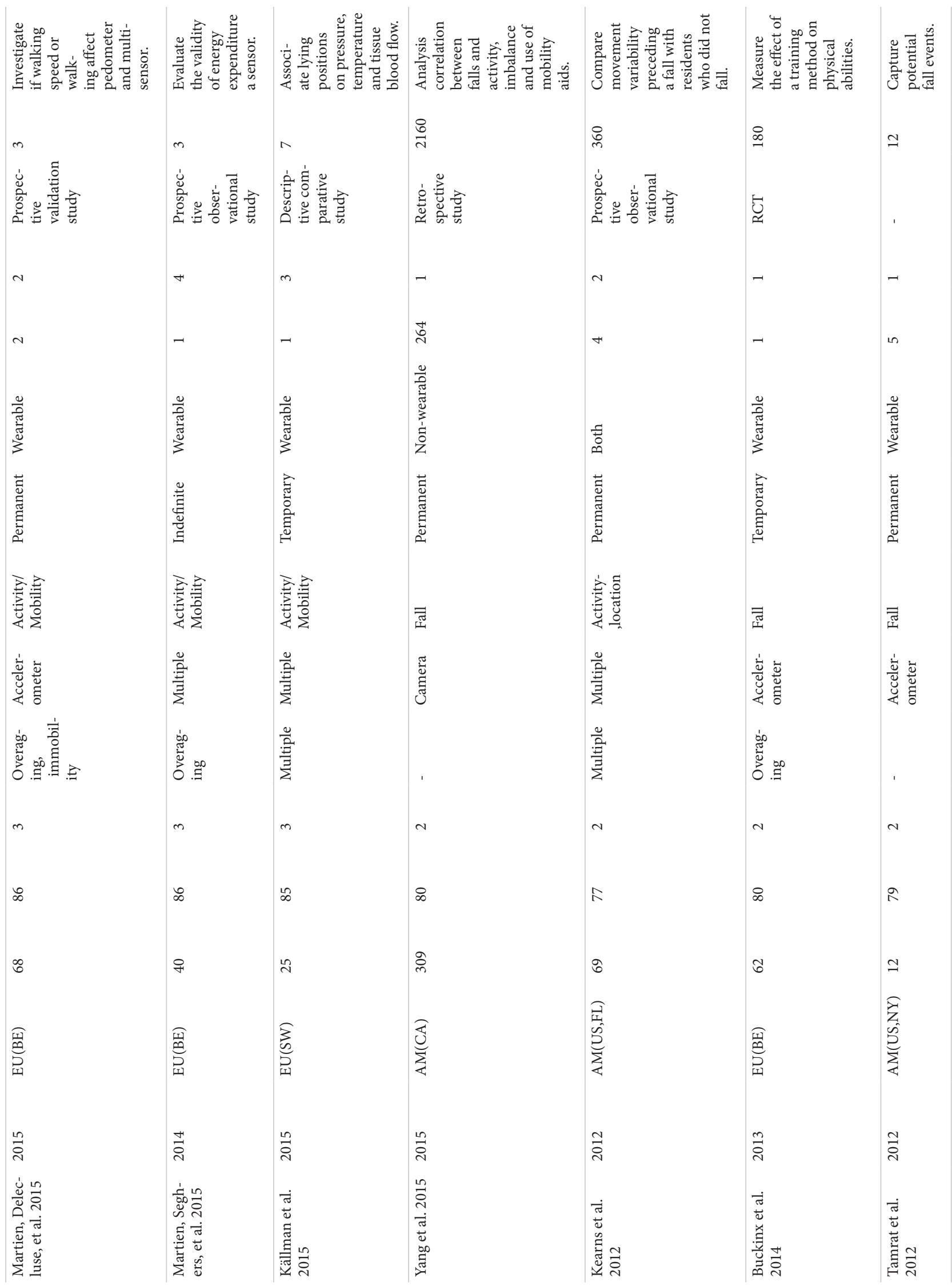




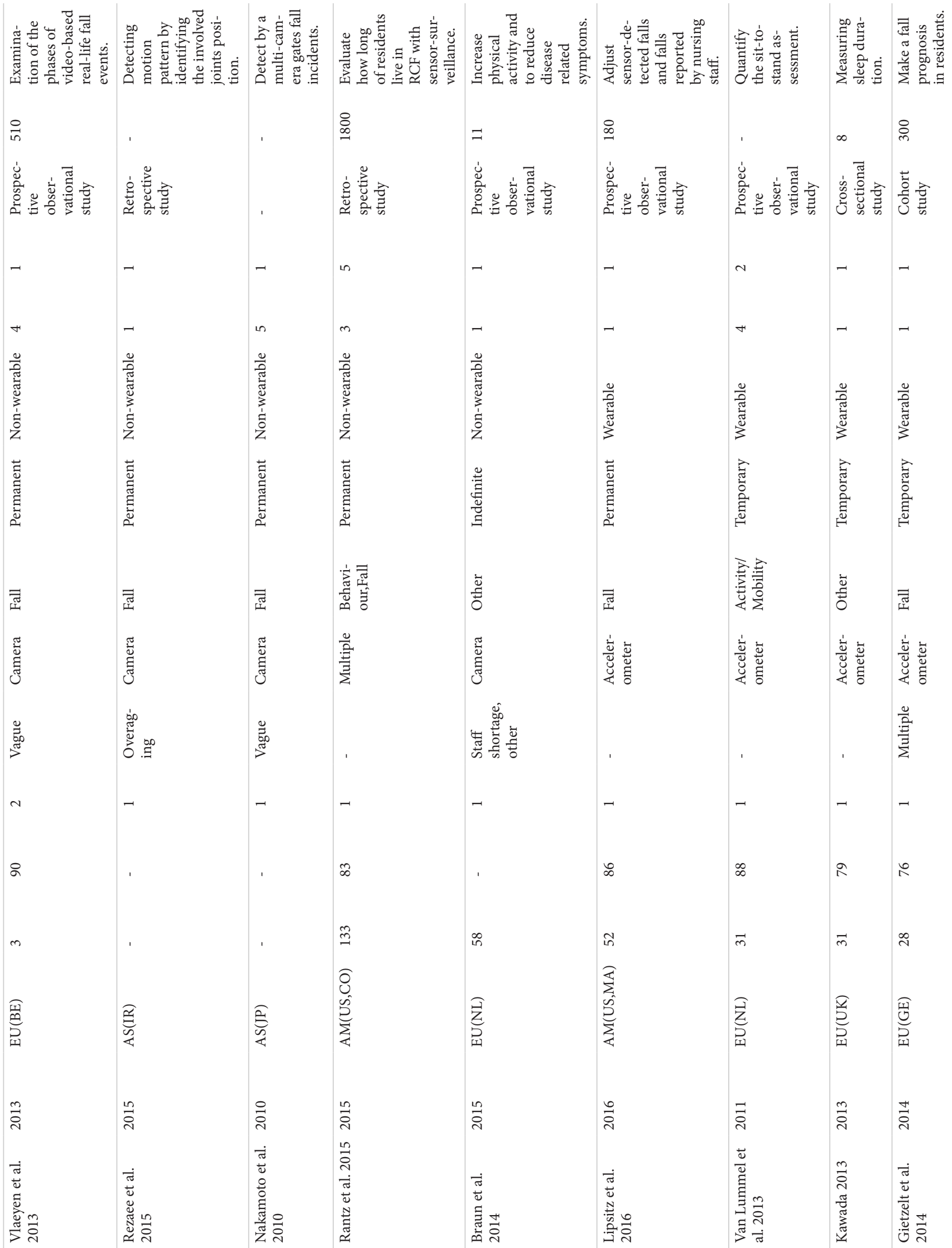




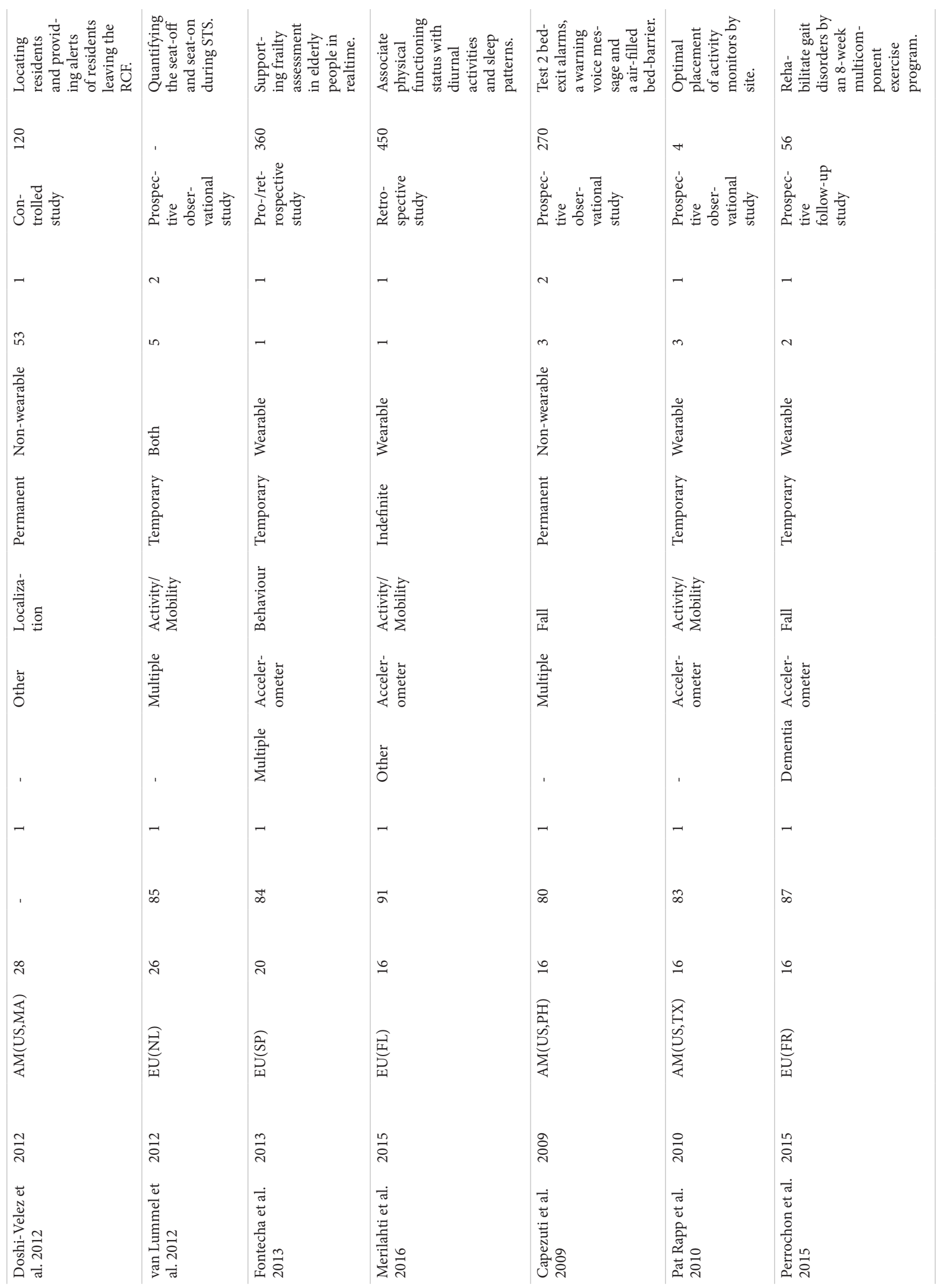




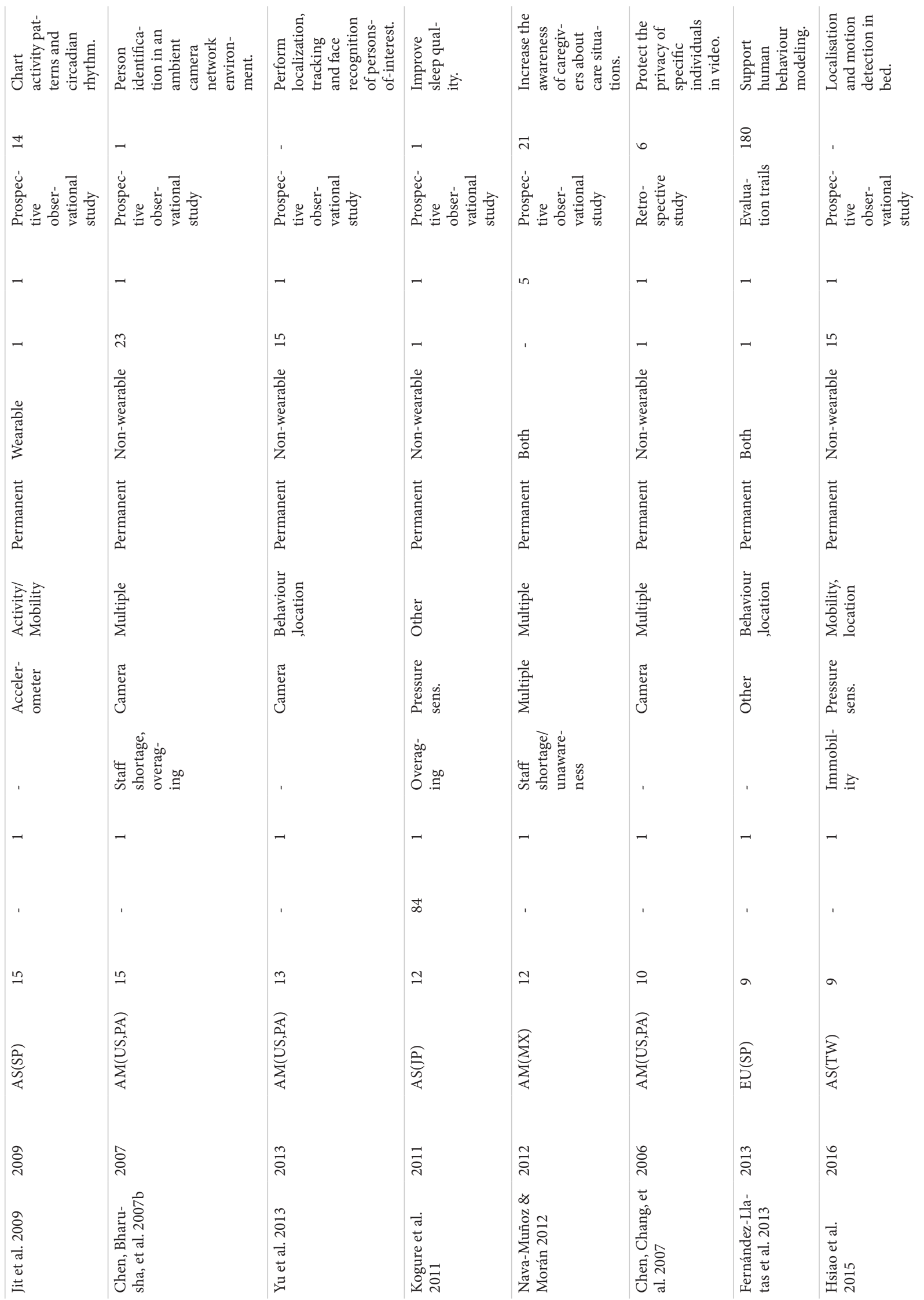




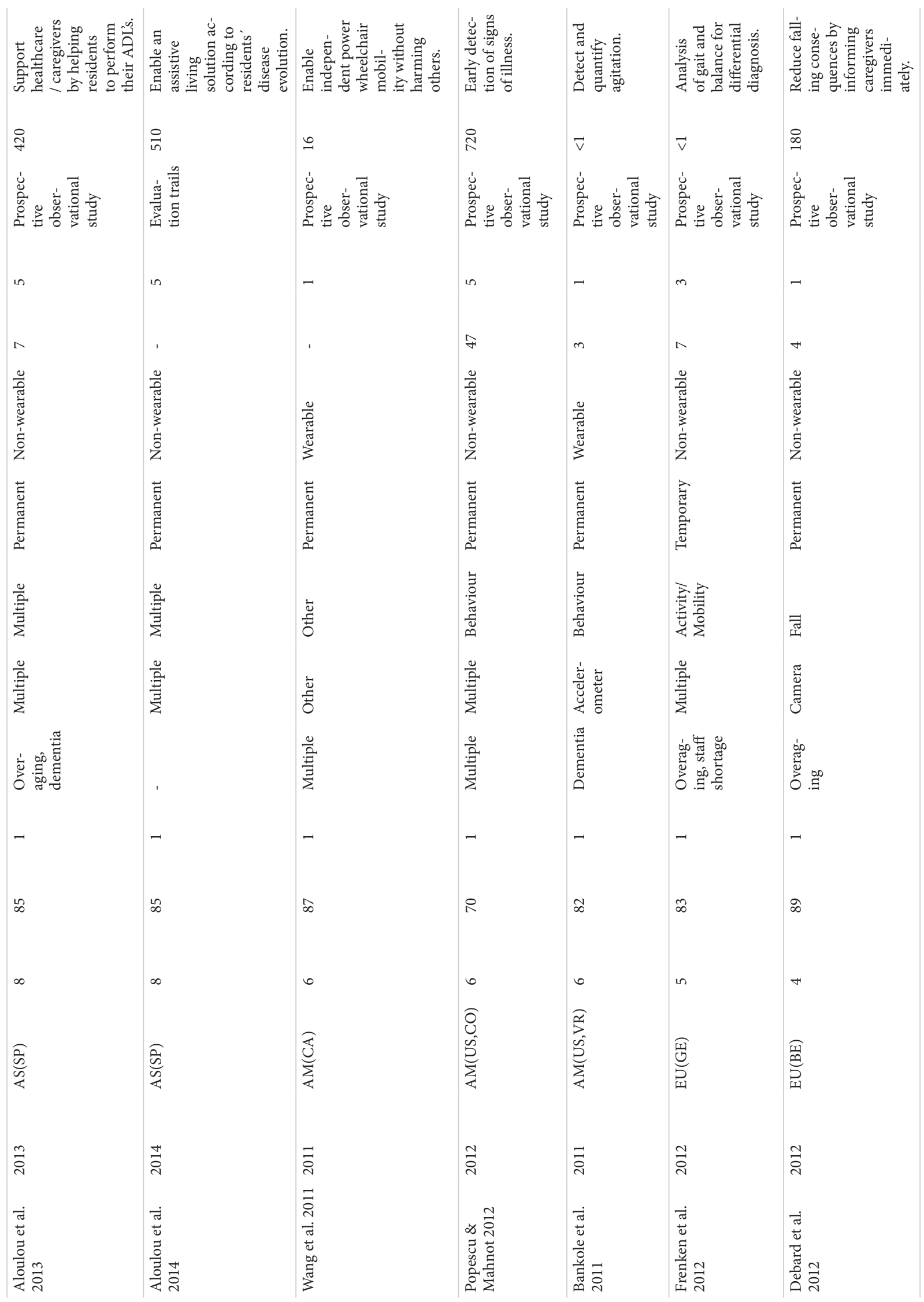


Fehling et al. Journal of Nursing 2017,

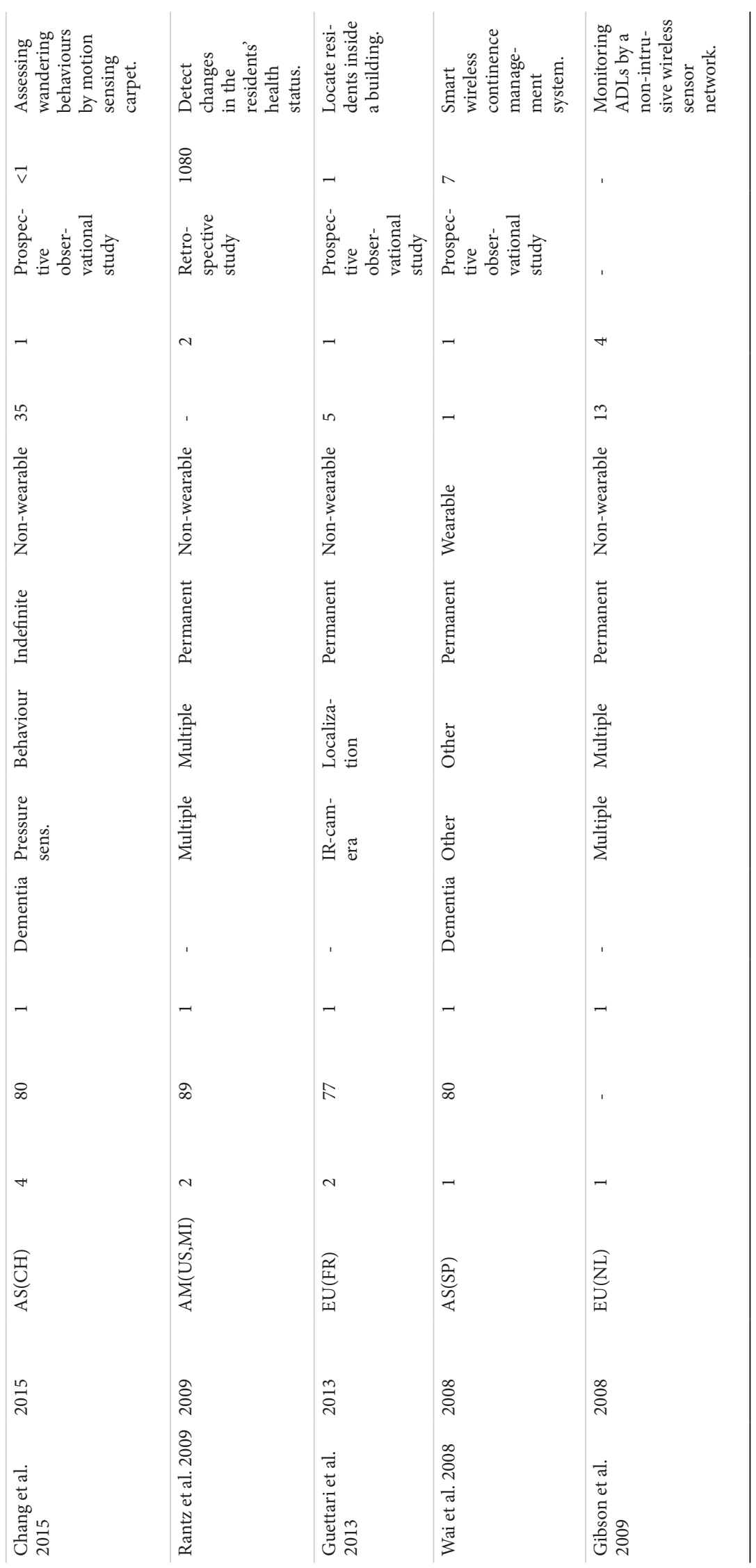


Fehling et al. Journal of Nursing 2017,

http://www.hoajonline.com/journals/pdf/2056-9157-4-1.pdf

doi: $10.7243 / 2056-9157-4-1$

Table 2. Study quality. Component ratings: C_A) Selection bias; C_B) Study design; C_C) Confounders; C_D) Blinding; C_E) Data collection methods; C_F) Withdrawals and drop-outs; C_G) Intervention integrity; C_H) Analyses. Outcome: Strong= $\Delta$, Moderate $=\emptyset$, Weak $=\nabla$.

\begin{tabular}{|c|c|c|c|c|c|c|c|c|c|}
\hline Study & C_A & C_B & C_C & C_D & C_E & C_F & C_G & C_H & SUM \\
\hline Aloulou et al. 2013 & $\triangle$ & $\diamond$ & $\nabla$ & $\nabla$ & $\nabla$ & $\nabla$ & $\diamond$ & $\triangle$ & $>$ \\
\hline Debard et al. 2012 & $\nabla$ & $\nabla$ & $\nabla$ & $\nabla$ & $\nabla$ & $\diamond$ & $\nabla$ & $\diamond$ & $\boldsymbol{\nabla}$ \\
\hline Huizing et al. 2009 & $\triangle$ & $\triangle$ & $\triangle$ & $\diamond$ & $\triangle$ & $\diamond$ & $\triangle$ & $\triangle$ & $\boldsymbol{\Delta}$ \\
\hline Jit et al. 2009 & $\diamond$ & $\diamond$ & $\diamond$ & $\nabla$ & $\nabla$ & $\diamond$ & $\triangle$ & $\triangle$ & $\bullet$ \\
\hline Chen, Chang, et al. 2007 & $\diamond$ & $\diamond$ & $\nabla$ & $\nabla$ & $\nabla$ & $\nabla$ & $\diamond$ & $\diamond$ & $\boldsymbol{\nabla}$ \\
\hline Lipsitz et al. 2016 & $\triangle$ & $\diamond$ & $\nabla$ & $\nabla$ & $\nabla$ & $\nabla$ & $\triangle$ & $\diamond$ & $\diamond$ \\
\hline Kearns et al. 2012 & $\triangle$ & $\diamond$ & $\nabla$ & $\nabla$ & $\triangle$ & $\diamond$ & $\triangle$ & $\triangle$ & $\boldsymbol{\Delta}$ \\
\hline Fernández-Llatas et al. 2013 & $\diamond$ & $\diamond$ & $\nabla$ & $\nabla$ & $\nabla$ & $\nabla$ & $\triangle$ & $\diamond$ & $\boldsymbol{\nabla}$ \\
\hline Koczy et al. 2011 & $\triangle$ & $\triangle$ & $\triangle$ & $\diamond$ & $\triangle$ & $\diamond$ & $\triangle$ & $\triangle$ & $\boldsymbol{\Delta}$ \\
\hline Gietzelt et al. 2014 & $\diamond$ & $\diamond$ & $\nabla$ & $\nabla$ & $\nabla$ & $\diamond$ & $\triangle$ & $\triangle$ & $\diamond$ \\
\hline Braun et al. 2014 & $\diamond$ & $\nabla$ & $\nabla$ & $\nabla$ & $\nabla$ & $\nabla$ & $\nabla$ & $\diamond$ & $\boldsymbol{\nabla}$ \\
\hline Yuet al. 2013 & $\triangle$ & $\diamond$ & $\nabla$ & $\nabla$ & $\nabla$ & $\nabla$ & $\diamond$ & $\diamond$ & $\boldsymbol{\nabla}$ \\
\hline Van Lummel et al. 2013 & $\nabla$ & $\diamond$ & $\diamond$ & $\nabla$ & $\diamond$ & $\nabla$ & $\triangle$ & $\triangle$ & $\diamond$ \\
\hline Van Lummel et al. 2013 & $\nabla$ & $\diamond$ & $\diamond$ & $\nabla$ & $\diamond$ & $\nabla$ & $\triangle$ & $\triangle$ & $\diamond$ \\
\hline Wang et al. 2011 & $\diamond$ & $\nabla$ & $\nabla$ & $\nabla$ & $\nabla$ & $\diamond$ & $\diamond$ & $\diamond$ & $\boldsymbol{\nabla}$ \\
\hline Doshi-Velez et al. 2012 & $\triangle$ & $\diamond$ & $\triangle$ & $\nabla$ & $\nabla$ & $\nabla$ & $\triangle$ & $\diamond$ & 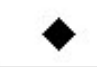 \\
\hline Wai et al. 2008 & $\triangle$ & $\diamond$ & $\nabla$ & $\nabla$ & $\nabla$ & $\nabla$ & $\diamond$ & $\diamond$ & $\boldsymbol{\nabla}$ \\
\hline Hsiao et al. 2015 & $\nabla$ & $\nabla$ & $\nabla$ & $\nabla$ & $\nabla$ & $\nabla$ & $\diamond$ & $\diamond$ & $\boldsymbol{\nabla}$ \\
\hline Frenken et al. 2012 & $\nabla$ & $\nabla$ & $\nabla$ & $\nabla$ & $\triangle$ & $\triangle$ & $\triangle$ & $\triangle$ & \\
\hline Yang et al. 2015 & $\triangle$ & $\diamond$ & $\nabla$ & $\nabla$ & $\nabla$ & $\nabla$ & $\triangle$ & $\triangle$ & 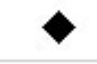 \\
\hline Aloulou et al. 2014 & $\nabla$ & $\nabla$ & $\nabla$ & $\nabla$ & $\nabla$ & $\nabla$ & $\diamond$ & $\nabla$ & $\nabla$ \\
\hline
\end{tabular}


Rantz et al. 2009

Källman et al. 2015

Fontecha et al. 2013

Kawada 2013

Schwesig et al. 2012

van Lummel et al. 2012

Vlaeyen et al. 2013

Rezaee et al. 2015

Merilahti et al. 2016

Popescu \&Mahnot 2012

Chen, Bharusha, et al. 2007b

Kogure et al. 2011

Capezuti et al. 2009

Tamrat et al. 2012

Pat Rapp et al. 2010

Perrochon et al. 2015

Nakamoto et al. 2010

Bankole et al. 2011

Phillips et al. 2015

Guettari et al.2013

Nava-Muñoz\&Morán 2012

Martien, Delecluse, et al. 2015

\begin{tabular}{|c|c|c|c|c|c|c|c|c|}
\hline$\nabla$ & $\nabla$ & $\nabla$ & $\nabla$ & $\nabla$ & $\diamond$ & $\nabla$ & $\Delta$ & $\boldsymbol{\nabla}$ \\
\hline$\Delta$ & $\diamond$ & $\nabla$ & $\nabla$ & $\nabla$ & $\nabla$ & $\Delta$ & $\Delta$ & $\gamma$ \\
\hline$\nabla$ & $\diamond$ & $\nabla$ & $\nabla$ & $\nabla$ & $\nabla$ & $\Delta$ & $\diamond$ & $\boldsymbol{\nabla}$ \\
\hline$\diamond$ & $\nabla$ & $\nabla$ & $\nabla$ & $\nabla$ & $\nabla$ & $\Delta$ & $\Delta$ & $\boldsymbol{\nabla}$ \\
\hline$\Delta$ & $\diamond$ & $\nabla$ & $\nabla$ & $\Delta$ & $\Delta$ & $\Delta$ & $\triangle$ & $\boldsymbol{\Delta}$ \\
\hline$\diamond$ & $\diamond$ & $\nabla$ & $\nabla$ & $\Delta$ & $\diamond$ & $\diamond$ & $\diamond$ & 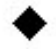 \\
\hline$\Delta$ & $\diamond$ & $\nabla$ & $\nabla$ & $\nabla$ & $\nabla$ & $\diamond$ & $\Delta$ & 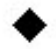 \\
\hline$\diamond$ & $\diamond$ & $\nabla$ & $\nabla$ & $\nabla$ & $\nabla$ & $\diamond$ & $\Delta$ & $\nabla$ \\
\hline$\Delta$ & $\diamond$ & $\nabla$ & $\nabla$ & $\Delta$ & $\nabla$ & $\Delta$ & $\Delta$ & $\boldsymbol{\Delta}$ \\
\hline$\diamond$ & $\diamond$ & $\nabla$ & $\nabla$ & $\nabla$ & $\nabla$ & $\diamond$ & $\Delta$ & $\nabla$ \\
\hline$\nabla$ & $\nabla$ & $\nabla$ & $\nabla$ & $\nabla$ & $\nabla$ & $\diamond$ & $\diamond$ & $\nabla$ \\
\hline$\diamond$ & $\nabla$ & $\diamond$ & $\nabla$ & $\diamond$ & $\nabla$ & $\Delta$ & $\triangle$ & $\bullet$ \\
\hline$\diamond$ & $\diamond$ & $\nabla$ & $\nabla$ & $\nabla$ & $\Delta$ & $\Delta$ & $\Delta$ & $\bullet$ \\
\hline$\diamond$ & $\diamond$ & $\nabla$ & $\nabla$ & $\nabla$ & $\nabla$ & $\nabla$ & $\diamond$ & $\boldsymbol{\nabla}$ \\
\hline$\Delta$ & $\diamond$ & $\nabla$ & $\nabla$ & $\Delta$ & $\Delta$ & $\Delta$ & $\Delta$ & $\boldsymbol{\Delta}$ \\
\hline$\Delta$ & $\diamond$ & $\nabla$ & $\nabla$ & $\diamond$ & $\diamond$ & $\Delta$ & $\diamond$ & $\gamma$ \\
\hline$\nabla$ & $\nabla$ & $\nabla$ & $\nabla$ & $\nabla$ & $\nabla$ & $\Delta$ & $\diamond$ & $\nabla$ \\
\hline$\diamond$ & $\diamond$ & $\nabla$ & $\nabla$ & $\Delta$ & $\Delta$ & $\Delta$ & $\Delta$ & $\boldsymbol{\Delta}$ \\
\hline$\diamond$ & $\diamond$ & $\nabla$ & $\nabla$ & $\nabla$ & $\nabla$ & $\Delta$ & $\Delta$ & $>$ \\
\hline$\nabla$ & $\nabla$ & $\nabla$ & $\nabla$ & $\nabla$ & $\nabla$ & $\diamond$ & $\diamond$ & $\nabla$ \\
\hline$\nabla$ & $\diamond$ & $\nabla$ & $\nabla$ & $\nabla$ & $\diamond$ & $\diamond$ & $\Delta$ & 7 \\
\hline$\diamond$ & $\diamond$ & $\nabla$ & $\nabla$ & $\nabla$ & $\triangle$ & $\Delta$ & $\diamond$ & \\
\hline
\end{tabular}


Fehling et al. Journal of Nursing 2017,

http://www.hoajonline.com/journals/pdf/2056-9157-4-1.pdf

\begin{tabular}{|c|c|c|c|c|c|c|c|c|c|}
\hline Martien, Seghers, et al. 2015 & $\diamond$ & $\diamond$ & $\nabla$ & $\nabla$ & $\diamond$ & $\diamond$ & $\triangle$ & $\triangle$ & 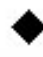 \\
\hline Rantz et al. 2015 & $\triangle$ & $\diamond$ & $\nabla$ & $\nabla$ & $\diamond$ & $\triangle$ & $\triangle$ & $\triangle$ & $\boldsymbol{\Delta}$ \\
\hline Buckinx et al. 2014 & $\triangle$ & $\triangle$ & $\triangle$ & $\triangle$ & $\nabla$ & $\triangle$ & $\triangle$ & $\triangle$ & $\boldsymbol{\Delta}$ \\
\hline Kangas et al. 2009 & $\triangle$ & $\diamond$ & $\nabla$ & $\nabla$ & $\nabla$ & $\nabla$ & $\diamond$ & $\triangle$ & \\
\hline Chung et al. 2015 & $\diamond$ & $\diamond$ & $\nabla$ & $\nabla$ & $\nabla$ & $\nabla$ & $\triangle$ & $\triangle$ & rat \\
\hline Zhu et al. 2014 & $\diamond$ & $\diamond$ & $\nabla$ & $\nabla$ & $\nabla$ & $\nabla$ & $\diamond$ & $\diamond$ & 7 \\
\hline Gibson et al. 2009 & $\nabla$ & $\nabla$ & $\nabla$ & $\nabla$ & $\nabla$ & $\nabla$ & $\diamond$ & $\nabla$ & \\
\hline
\end{tabular}

Table 3. Samples inclusion / exclusion criteria.

\begin{tabular}{llll}
\hline Inclusion criteria $(\mathbf{n}=\mathbf{4 4})$ & Frequency & Exclusion criteria $(\mathbf{n}=\mathbf{2 9})$ & Frequency \\
\hline - mild or moderate cognitive impairment related & 12 & - cardiac pacemaker & 3 \\
to dementia, evaluated with MMSE & & & \\
- previous falls and high fall risk, respectively. & 9 & - recent fracture & 3 \\
- walking ability & 6 & - psychological diseases & 3 \\
- at least 65 or 70 years old & 5 & & \\
\hline
\end{tabular}

bined various types of SeTe devices (Table 1). Microswitches [17], active bracelets [18], tablet computers with WiFi-based localization system [19], and moisture sensors [20] were each applied once. The interest in accelerometers and cameras as SeTe devices in RCFs has remained unchanged over the past ten years. While the number of studies using pressure sensors decreased by two-thirds in the past ten years, the number of studies that used several varieties SeTe devices has doubled to $33 \%$.

Only five studies, mainly older studies, presented prototypes of newly developed SeTe. All other studies tested SeTe devices that were already established in the RCFs.

Of the scientists, $23 \%$ justified the choice of SeTe devices with the fact that it had already proved its worth. Further reasons were that the SeTe tested was more accurate than other SeTe $(11 \%)$ or that it was less obtrusive $(9 \%)$ or small and light (7\%). Four scientists used the SeTe opportunistically: they had been previously installed by scientists.

In $73 \%$ of the studies gave reasons why SeTe should move into the RCFs at all. Arguments that have been mentioned several times are summarized in Figure 4.

Of the research teams, $41 \%$ chose SeTe devices that were wearable, mostly accelerometers. The preferred SeTe devices were non-wearable (51\%). Figure 3 shows the location where the scientists had placed the SeTe devices.

Of the studies included, $43 \%$ used one sensor and $82 \%$ used less than ten sensors (Table 1). The study by Yang et al. [21] stands out because they analyzed the data from 264 cameras. The more sensors were used, the more the value was placed on software engineering and less on the SeTe hardware. The use of a larger number of sensors allowed studying more complex targets, such as behavioral analysis or "detection of changing patterns in the performance of ADLs" [22], which led to more satisfying results for the scientists.

A comparison of studies using only one type of SeTe $(n=32)$ with those using more than one type $(n=17)$ led to the following associations. The studies using various types of SeTe devices

- had fewer participants,

- on average took 2.4 times longer,

- used fewer sensors,

- rather had multidimensional objectives such as "an assistive solution that can adapt to the changing needs" [23], and

- included less unsatisfactory reports by the authors

- than the papers that used only one SeTe type.

Several studies using accelerometers, cameras, IR devices, active bracelets, or pressure sensors commented that they could not adequately adjust their SeTe devices for their participants. These papers have in common that they used only one type of SeTe device. The research groups which did not complain about this problem on average combined more than 1.8 types of SeTe devices. 
Fehling et al. Journal of Nursing 2017,
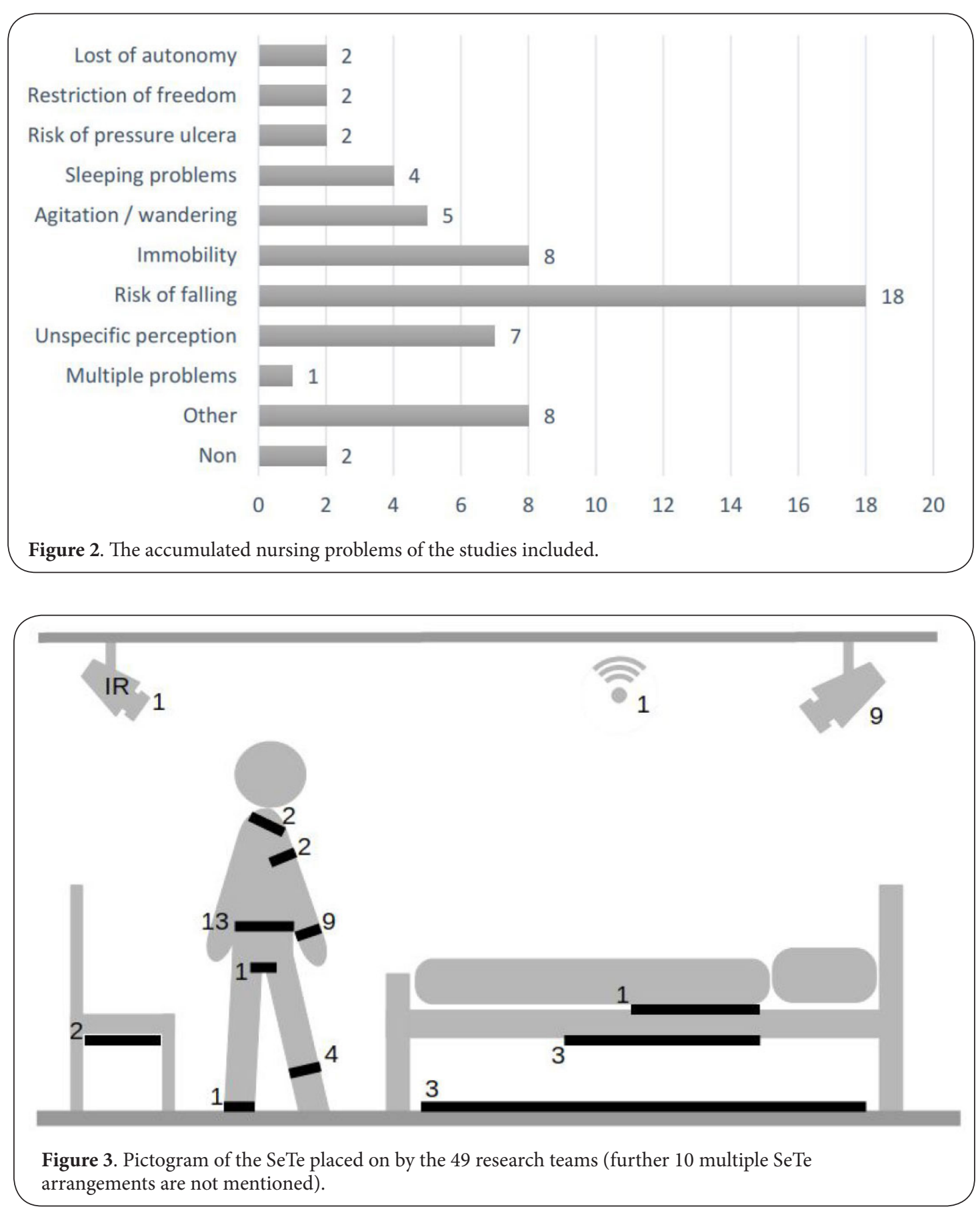

Of the SeTe devices used in the studies, $84 \%$ measured motion or changes in motion. Consequently, most of the research teams had examined motion-related events such as falls (26\%), activity/mobility (25\%), and behavior (14\%). Investigations of falls and risks of falling using SeTe devices have doubled over the past ten years. Only a few studies focused on non-motion measurements such as localization (Doshi-Velez et al., 2012), skin temperatures and pneumatic pressure (Källman et al., 2015), or moisture (Wai et al., 2008).
Two-thirds of the 49 studies preferred the permanent surveillance by SeTe devices. Only $22 \%$ of the research teams used SeTe devices temporarily to diagnose frailty [24], sleeping patterns [25], fall-risk probability [26], and mobility (seat-off, seat-on [27], TUG [28], and sit-to-stand [29].

\section{Technical Problems and Ethical Considerations}

In this critical systematic review, 33 studies mentioned a total of 68 technical problems. Scientists using accelerometers 


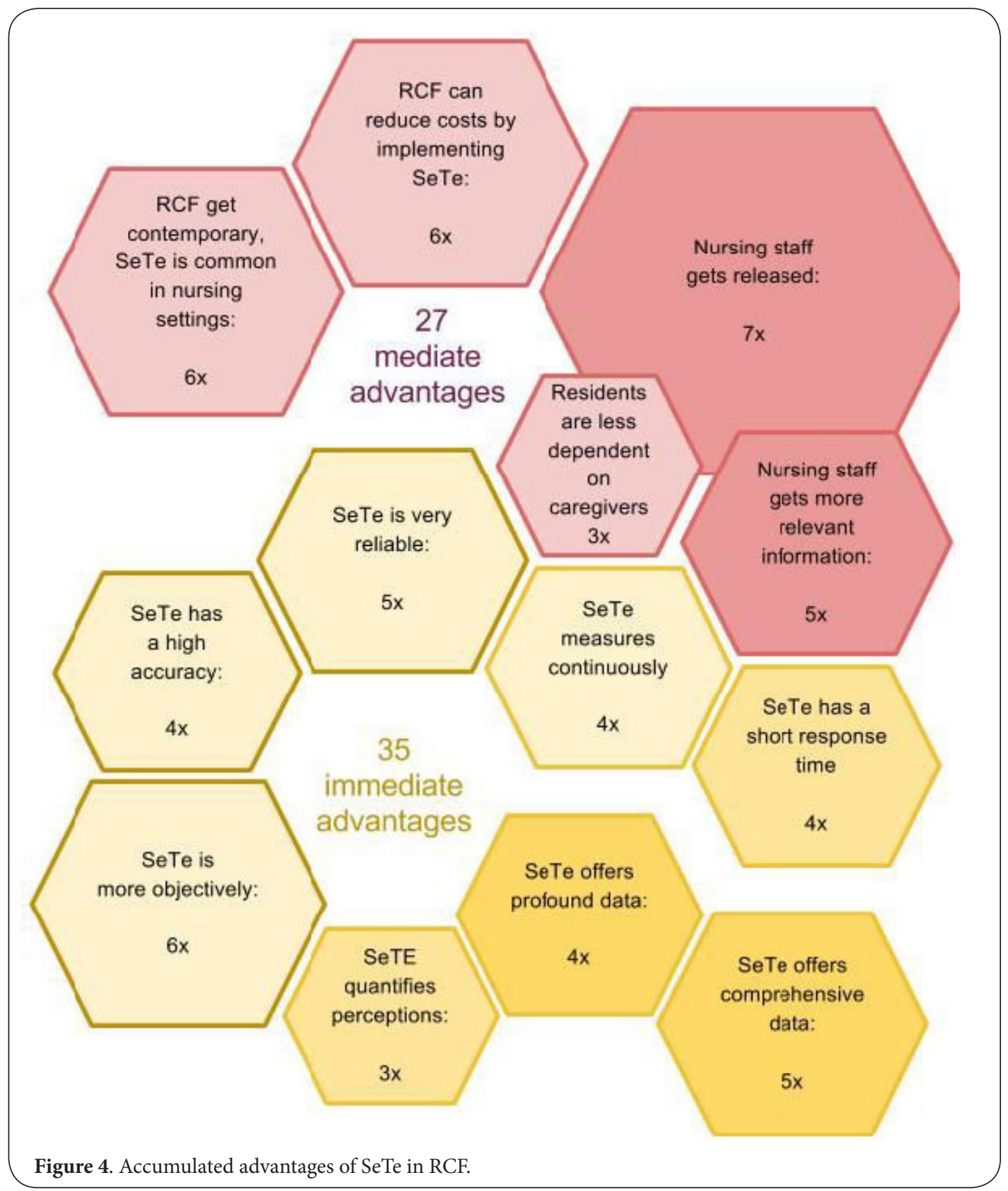

described difficulties of limited battery life, interruptions in measurements, and data transmission issues. The studies using cameras complained about the large amounts of data and the limitations in the monitoring: "falls of the participants outside the rooms could not be detected, as the Fall-Cam system was restricted to this area" [30] and "for instance, it would be problematic when there are reflections or large shadows in frames" [31].

Technical problems with SeTe devices were mentioned several times:

- Artifacts or inaccurate measurements leading to false alarms (12x);
- Inability of SeTe devices to be adjusted individually for each participant $(8 \mathrm{x})$;

- Interruptions in measurement because participants had dropped or lost the SeTe device (8x);

- Monitoring was impaired by reflections, shadows, or moving doors (5x);

- Data transfer interruptions and missing data due to, for example, loss of network connectivity (4x);

- $\quad$ Limited battery life (4x);

- The nursing problem could not be described adequately as a software algorithm (4x);

- Excessive amounts of data (4x); 
- $\quad$ Problems installing the SeTe devices (4x);

- Overlapping monitoring data of different individuals (3x); While almost all authors cited the ethical approval for their research, only one-quarter of the studies mention current or potential ethical considerations regarding the surveillance of residents by SeTe devices.

Of the studies, $69 \%$ used well-visible SeTe devices. Other SeTe devices could be used in secret. For example, motionsensing mats [32] or carpets [33], SeTe devices under [32,34] or on an edge [35] of a mattress, under a bed sheet [36], or as a contact sensor [17] can easily be installed in secret. The question of whether SeTe surveillance could potentially be secretly installed was not discussed in any study.

The privacy of the residents was mentioned in 12 studies. These concerns often led to a limitation of the surveillance: "for privacy reasons, we did not plan to install a camera in the bathroom" [4] or "the body texture is obscured, and only body contours are partially preserved, which protects the identity" [37]. Alternatively, for example, switches were installed for deactivating the surveillance $[19,30]$. Arrangements for the protection of privacy were gratefully accepted by the participants: "another interesting outcome of our focus groups was the residents' willingness to accept a camera sensor in their apartment as long as only the silhouette of the person is captured." [38].

Undoubtedly, the acceptance of SeTe by the participants will influence the future of such surveillance technologies in RCFs. Of the studies, $63 \%$ did not comment on the acceptance of SeTe. One-third of the other studies indicated that the participants or the nursing staff had provided a positive feedback: "No study subjects mentioned any feeling of stigma from wearing the devices within the nursing facility. $83.5 \%$ of the study subjects stated that they would feel comfortable wearing the devices in public." [39]. "Overall, staff viewed the technology as positive and thought that a fully operational camera system might help their work." [30].

The feedback of five studies was ambivalent, and two studies provided a negative feedback from the participants. "Measuring this sleep quality over long periods is very inconvenient, especially for the elderly" [34]; " [...] the belt pack and waist strap were subject to urine odor and dampness" [40]; "Twenty-six participants (38\%) disliked wearing wristbands" [41].

\section{Discussion}

\section{Dissatisfaction in study quality and sample}

Of the 49 studies, $18 \%$ were rated good quality by the EPHPP quality assessment tool. However, $43 \%$ found the quality of the studies weak (Table 2). Thus, the total quality of the studies reviewed is not significantly different from the findings of other reviews in the nursing journals [42-44]. This, for example, depends on the selection and description of the sample. While the number of participants increased by onethird in the recent studies, the number of RCFs involved in these 49 studies was often too low for transferring the results to other RCFs. Possibly, the research teams had not been able to recruit more RCFs for their research, or perhaps because RCFs are rarely involved in research projects. Studies that had recruited an above-average number of participants and RCFs had focused more on the nursing problems and used SeTe devices only as a means to an end. From the point of view of nursing science, this approach was certainly welcome [45].

The mobility/activity of the participants was the focus of many studies with participants of all ages and is thus a plausible basis for the prevailing opinion that old people, in general, are physically less active $[46,47]$. In contrast, the researchers who had chosen behavioral patterns or tracking as objectives for their studies only had participants under 85 years. Why these studies did not include very old participants should be investigated in a future study.

Only two studies named RCF-specific reasons in choosing their sample; all other research teams chose the RCFs for pragmatic or opportune reasons. The advantage of the latter is obvious: the results of SeTe studies can be extended to other areas of health care in the future. However, SeTe is not specifically tailored to RCFs and their residents, and this may generate unsatisfactory results in the future.

The 15 research groups which did not describe the inclusion and exclusion criteria of the participating residents might be confronted with the accusation that they had chosen their participants arbitrarily. The perception of the inhabitants and, consequently, the quality of the study must be seriously questioned for the studies in which not even mention the age of the participants is mentioned (Table 1).

However, there is the positive trend in the papers to clarify the criteria for the inclusion and exclusion of the participation of residents. On average, these studies are two years newer than those that described the participants superficially or not at all.

\section{Underestimated Nursing Problems}

Although nursing problems pursued in the studies were heterogeneous (Figure 2), 41 of the 49 papers identified a single variable for the SeTe employed: motion or motion change. In the case of falls, it is the sensory motion detection that is predominantly conclusive. However, nursing scientists have repeatedly reported that falls in the elderly can have causes attributed to multiple intrinsic and extrinsic factors $[36,48,49]$. A simple motion measurement cannot account for all this, of which professional caregivers are surely aware of. However, RCF residents and their relatives could be taught that complex events such as falls, immobility, or even behavioral patterns could be measured or even predicted using the help of a simple motion sensor.

From a holistic perspective on nursing problems, the involvement of nursing scientists is certainly inevitable [50] [51]. Nursing scientists were only inadequately involved in the 49 studies of this review, which can be seen by that only a few studies had defined the nursing problem investigated. 
Fehling et al. Journal of Nursing 2017,

Neglecting to define the nursing problem or describing it as having only one cause will make it difficult to choose an appropriate SeTe, and specifying the software algorithms becomes problematic. For example, Kawada [25] equated sleep deficit with the sleep duration that he examined. In his study, the "sleep duration was calculated as the total of 'sleep' epochs from 21:00 $\mathrm{h}$ to $06: 00 \mathrm{~h}$ ". This arbitrary time frame is not applicable to all residents of RCFs, nor have other causes of sleep deficit been considered, such as interruptions of sleep, the sleep depth, or trouble of getting to sleep. Three research teams admitted that they had difficulties in identifying falling events from non-falling events: "It is therefore critical that the algorithm is precise enough to accurately discern a fall event but specific enough to distinguish between other movements and true fall events" [39].

Kearns et al. used a comprehensive definition for a nursing problem: "Falls are defined as an unintended movement from an elevated position to a position on the surface on which the person was either standing or from a higher surface such as a chair, with no elaboration of the circumstances surrounding the fall" [41]. The complexity of the nursing problems, which is only revealed by such definitions, represents an equally complex challenge for the SeTe and its software algorithms. How can the SeTe or its software detect "unintended movements"? This is probably not done by a motion sensor on the arm.

\section{Less convincing SeTe preferences}

The reasons for selecting a SeTe device type revealed two diametric positions in the choice of wearable or non-wearable SeTe devices. For both, representatives claimed that their SeTe was more accurate, more objective, more reliable, and more discreet. Fontecha et al. [24] wrote that the use of wearable SeTe in health care has increased significantly in recent years and that wearable SeTe is always easily used and inexpensive. Wearable devices "can be positioned anywhere on the body with low patient awareness [...]. This makes it possible to move from the lab to daily life settings." [27].

The scientists who proposed SeTe as unsuitable gave the following arguments:

- "ambient sensors are less obtrusive [than wearable ones], make patients not feel like being tested" [28];

- "patients with dementia tend to 'fiddle' with things within easy reach." [52];

- a camera "is contactless and does not require initiative of the person [...] in case the device is button operated [...], some persons with (mild) cognitive impairment are not always able to activate the alarm system due to the complexity of issues around the use of call alarms" [4];

- "health care professionals might not be able to correctly handle [wearable SeTe]"

- the residents' compliance is irrelevant for non-wearable SeTe [34];

- they have often been proven as successful $[30,53]$.

Future intervention studies should compare the advantages and the disadvantages of wearable and non-wearable SeTe, integrating the wishes and needs of the residents. Critical reviews already exist in juxtaposition [54]. Such findings would probably eliminate another phenomenon that appeared in this review: only three research teams used the same SeTe product. This could be related to the wide range of SeTe manufacturers or the high dynamics of SeTe development. From the meta-level perspective of this review, however, the impression arises that the research teams worldwide are isolated from each other; therefore, each review starts at zero and does not build on the findings of the others [55].

\section{A disappointing ethical debate}

The endeavor to protect and improve the privacy, security, and autonomy of residents has been mentioned in some of the studies involved. The majority of the studies, however, were not aware of the need to consider the ethical aspects of their scientific work $[\mathbf{5 6 , 5 7 ]}$. Studies which, for instance, used trackers [18] and face-recognition [58], or which had the intention of sharing these data with the electronic health record [41] should take data security into account [59]. This includes the potentially unsecure data transmission from a SeTe device to servers via WiFi [19], Bluetooth $[19,27]$, or a mobile phone [60].

There is no doubt that even potentially invisible SeTe surveillance will be used to improve the safety of the RCF residents. However, its ethical concerns and the extent of surveillance in RCFs are certainly worth a social and scientific debate. This debate should be conducted before the commercialization of SeTe in RCFs leaves little room for decision-making [61,62]. Regrettably, none of the studies of this review has mentioned the potential covert use of SeTe surveillance, either by accelerometers, cameras, or trackers.

However, it must be pointed out that the older studies in this review have used SeTe devices six times more covertly than the recent studies. In the recent studies, the number of critical remarks on ethical questions regarding the surveillance by SeTe has doubled. It can be deduced that there is a growing critical, reflective, self-understanding of scientists regarding surveillance by SeTe in RCFs.

\section{Conclusion}

Despite the need for qualitative improvement in many of the studies in this review, it is gratifying that the international interest in researching SeTe in RCFs has increased.

However, the small number of RCFs and participants involved and the scarcity of descriptions dealing with inclusion/exclusion criteria in many studies reduces the ability to transfer these findings to other RCFs.

Furthermore, there is a dominant, one-sided focus on the nursing problems of fall risk and immobility. This approach does not cover the primary current and potential challenges for RCFs. Also, few research teams have defined the nursing problem focused upon. Accordingly, they have underestimated 
Fehling et al. Journal of Nursing 2017,

the complexity of nursing problems. Presumably, this led to a wrong choice in SeTe and, therefore, unsatisfactory results. Nevertheless, several of the studies included have indicated that the use of various SeTe is beneficial, possibly because the more perspective data are combined.

Ethical dilemmas such as the potential replacement of the professional caregivers by SeTe, the threat to the privacy of residents of RCFs, or the potential of covert surveillance were hardly discussed. Nonetheless, the number of studies with critical remarks about SeTe has increased, and the acceptance of SeTe by the participants has more frequently been described as increasingly positive. Critical contemplations on surveillance by SeTe in RCFs were generally weak but appear to be increasing.

Apparently, most SeTe devices that have been tested by the research teams in RCFs were originally designed for another commercial market. As has been shown, this approach has led to unsatisfactory results for the researchers. Perhaps scientists intending to test SeTe in RCFs should proceed differently by first consulting the residents, professional caregivers, and nursing scientists about their requirements for useful and necessary technical surveillance.

The future use of SeTe in RCFs is certainly desirable and unavoidable. The prerequisite for a high acceptance of the surveillance by SeTe by all participants is not only the optimal hardware and software as well as the external validation of research results but also a scientific, ethical discourse on the balance between the autonomy and the security of the residents, a discourse that should be conducted on an interdisciplinary basis.

\section{Relevance to Clinical Practice}

This critical systematic review could indicate the following:

- Regarding the surveillance technology, interesting developments have been observed in RCFs over the past ten years. Certainly, a few of the SeTe devices presented will become marketable and possibly extensive used in RCFs. Surely, SeTe will support the nursing profession and at the same time, change it sustainably. Caregivers in RCFs should deal with these changes already now.

- The scientists mentioned many technical difficulties with the use of SeTe. These deficits will certainly be remedied in the coming years. Currently, however, RCFs should continue to use the SeTe cautiously.

- Many of the SeTe were originally not developed for the nursing profession. Perhaps that is why their technical feasibility had priority over their applicability to nursing. It could be shown in this review that the hardware and software of the SeTe were still insufficiently adjusted to nursing needs in RCFs.

- The studies partially presented nursing problems with perceptions and definitions that are remote from the professional caregiver approach. This could be because the caregivers in the RCFs where the SeTe was tested did not discuss the evidence-based nursing with the scientists who were involved in other disciplines. Professional caregivers in RCFs should be able to convey the growing self-image of nursing into similar research projects.

- Many scientists have neglected to take into account the ethical implications of SeTe surveillance. When it comes to the residents' privacy, data protection, and autonomy, or SeTe possibly replacing caregivers, the nursing profession is ultimately required to take a stand before permitting the extensive use of SeTe in RCFs, which leaves little room for decision-making.

\section{Limitations}

Despite using the Cochrane Collaboration Methodology and the PRISMA Principles, the final selection of the 49 studies have indicated a selection bias. It is possible that relevant studies were not included in this review due to the choice of databases and the selected keywords.

Since neither the quality of studies nor the scientific field from which they originated limited the eligibility, the focus and the quality of the 49 studies were heterogeneous. This heterogeneity made the quality assessment per EPHPP difficult. Finally, despite our efforts to consistently evaluate the 49 studies objectively, statements in the studies could be misinterpreted or over-interpreted.

\section{Competing interests}

The authors declare that they have no competing interests.

Authors' contributions

\begin{tabular}{|l|c|c|}
\hline Authors' contributions & PF & TD \\
\hline Research concept and design & $\checkmark$ & $\checkmark$ \\
\hline Collection and/or assembly of data & $\checkmark$ & -- \\
\hline Data analysis and interpretation & $\checkmark$ & $\checkmark$ \\
\hline Writing the article & $\checkmark$ & -- \\
\hline Critical revision of the article & $\checkmark$ & -- \\
\hline Final approval of article & $\checkmark$ & $\checkmark$ \\
\hline Statistical analysis & $\checkmark$ & $\checkmark$ \\
\hline
\end{tabular}

\section{Acknowledgement}

This study was not funded and there is no conflict of interest.

Publication history

Editor: Pamela gail Hawranik, Athabasca University, Canada. Received: 03-July-2017 Final Revised: 20-Sep-2017

Accepted: 18-Nov-2017 Published: 29-Nov-2017

\section{References}

1. Morrison A and Levy R. Fraction of nursing home admissions attributable to urinary incontinence. Value Health. 2006; 9:272-4. | Article I PubMed

2. Aloulou H, Mokhtari M, Tiberghien T, Biswas J, Phua C, Kenneth Lin JH and Yap P. Deployment of assistive living technology in a nursing home environment: methods and lessons learned. BMC Med Inform Decis Mak. 2013; 13:42. | Article | PubMed Abstract | PubMed FullText

3. Topo P. Technology Studies to Meet the Needs of People With Dementia and Their Caregivers. J Appl Gerontol. 2009; 28:5-37. | Article 
Fehling et al. Journal of Nursing 2017,

http://www.hoajonline.com/journals/pdf/2056-9157-4-1.pdf

doi: $10.7243 / 2056-9157-4-1$

4. Debard G, Karsmakers P, Deschodt M, Vlaeyen E, Dejaeger E and Milisen $\mathrm{K}$ et al. Camera-Based Fall Detection on Real World Data. Lecture Notes in Computer Science. 2012; 356-75. I Article

5. Lee WC, Dooley KE, Ory MG and Sumaya CV. Meeting the geriatric workforce shortage for long-term care: opinions from the field. Gerontol Geriatr Educ. 2013; 34:354-71. | Article | PubMed

6. Bakerjian D. Care of nursing home residents by advanced practice nurses. A review of the literature. Res Gerontol Nurs. 2008; 1:177-85. Article I PubMed

7. Kosse NM, Brands K, Bauer JM, Hortobagyi T and Lamoth CJ. Sensor technologies aiming at fall prevention in institutionalized old adults: a synthesis of current knowledge. Int J Med Inform. 2013; 82:743-52. | Article | PubMed

8. Zwijsen SA, Depla MF, Niemeijer AR, Francke AL and Hertogh CM. Surveillance technology: an alternative to physical restraints? A qualitative study among professionals working in nursing homes for people with dementia. Int J Nurs Stud. 2012; 49:212-9. | Article | PubMed

9. Peek ST, Wouters EJ, van Hoof J, Luijkx KG, Boeije HR and Vrijhoef $\mathrm{HJ}$. Factors influencing acceptance of technology for aging in place: a systematic review. Int J Med Inform. 2014; 83:235-48. | Article PubMed

10. Metzler TA and Barnes SJ. Three dialogues concerning robots in elder care. Nurs Philos. 2014; 15:4-13. | Article | PubMed

11. Shuster JJ. Review: Cochrane handbook for systematic reviews for interventions, Version 5.1.0, published 3/2011. Julian P.T. Higgins and Sally Green, Editors. Research Synthesis Methods 2011;2:126-30.

12. Moher D, Liberati A, Tetzlaff J and Altman DG. Preferred reporting items for systematic reviews and meta-analyses: the PRISMA statement. Ann Intern Med. 2009; 151:264-9. | Article | PubMed

13. de Bruin ED, Hartmann A, Uebelhart D, Murer K and Zijlstra W. Wearable systems for monitoring mobility-related activities in older people: a systematic review. Clin Rehabil. 2008; 22:878-95. | Article | PubMed

14. Higgins JPT and Green S. Assessment of study quality and risk of bias Handbook.cochrane.org. 2011. | Article

15. Koczy P, Becker C, Rapp K, Klie T, Beische D, Buchele G, Kleiner A, Guerra V, Rissmann U, Kurrle S and Bredthauer D. Effectiveness of a multifactorial intervention to reduce physical restraints in nursing home residents. J Am Geriatr Soc. 2011; 59:333-9. | Article I PubMed

16. Braun SM, Kleynen M, Bleijlevens MH, Moser A, Beurskens AJ and Lexis MA. "Interactive surfaces" technology as a potential tool to stimulate physical activity in psychogeriatric nursing home residents. Disabil Rehabil Assist Technol. 2014. | Article | PubMed

17. Wang RH, Gorski SM, Holliday PJ and Fernie GR. Evaluation of a Contact Sensor Skirt for an Anti-Collision Power Wheelchair for Older Adult Nursing Home Residents With Dementia: Safety and Mobility. Assist Technol. 2011; 23:117-34. | Article

18. Fernandez-Llatas C, Benedi JM, Garcia-Gomez JM and Traver V. Process mining for individualized behavior modeling using wireless tracking in nursing homes. Sensors (Basel). 2013; 13:15434-51. | Article | PubMed Abstract | PubMed FullText

19. Doshi-Velez F, Li W, Battat Y, Charrow B, Curtis D, Park JG, Hemachandra S, Velez J, Walsh C, Fredette D, Reimer B, Roy N and Teller S. Improving safety and operational efficiency in residential care settings with WiFibased localization. J Am Med Dir Assoc. 2012; 13:558-63. | Article | PubMed

20. Wai AA, Fook VF, Jayachandran M, Biswas J, Nugent C, Mulvenna M, Lee JE and Kiat PY. Smart wireless continence management system for persons with dementia. Telemed J E Health. 2008; 14:825-32. | Article | PubMed

21. Yang Y, Feldman F, Leung PM, Scott V and Robinovitch SN. Agreement between video footage and fall incident reports on the circumstances of falls in long-term care. J Am Med Dir Assoc. 2015; 16:388-94. | Article
| PubMed

22. Gibson C, Kasteren T and Kröse B. Monitoring homes with wireless sensor networks. 2008.

23. Aloulou H, Mokhtari M, Tiberghien T, Biswas J and Yap P. An adaptable and flexible framework for assistive living of cognitively impaired people. IEEE J Biomed Health Inform. 2014; 18:353-60. | Article | PubMed

24. Fontecha J, Hervas R, Bravo J and Navarro FJ. A mobile and ubiquitous approach for supporting frailty assessment in elderly people. J Med Internet Res. 2013; 15:e197. | Article | PubMed Abstract | PubMed FullText

25. Kawada T. Sleep duration for residents in the nursing home by accelerometer: a preliminary study. J Psychiatr Ment Health Nurs. 2013; 20:662-4. | Article | PubMed

26. Schwesig R, Fischer D, Lauenroth A, Becker S and Leuchte S. Can falls be predicted with gait analytical and posturographic measurement systems? A prospective follow-up study in a nursing home population. Clin Rehabil. 2013; 27:183-90. | Article | PubMed

27. van Lummel RC, Ainsworth E, Hausdorff JM, Lindemann U, Beek PJ and van Dieen JH. Validation of seat-off and seat-on in repeated sit-to-stand movements using a single-body-fixed sensor. Physiol Meas. 2012; 33:1855-67. | Article | PubMed

28. Frenken T, Brell M, Gövercin M, Wegel S and Hein A. aTUG: technical apparatus for gait and balance analysis within component-based Timed Up \& Go using mutual ambient sensors. J Ambient Intell Humaniz Comput. 2012; 4:759-78.

29. Van Lummel RC, Ainsworth E, Lindemann U, Zijlstra W, Chiari L, Van Campen $\mathrm{P}$ and Hausdorff JM. Automated approach for quantifying the repeated sit-to-stand using one body fixed sensor in young and older adults. Gait Posture. 2013; 38:153-6. | Article | PubMed

30. Vlaeyen E, Deschodt M, Debard G, Dejaeger E, Boonen S, Goedeme $T$, Vanrumste $B$ and Milisen $K$. Fall incidents unraveled: a series of $\mathbf{2 6}$ video-based real-life fall events in three frail older persons. $B M C$ Geriatr. 2013; 13:103. | Article | PubMed Abstract | PubMed FullText

31. Rezaee K, Haddadnia J and Delbari A. Modeling abnormal walking of the elderly to predict risk of the falls using Kalman filter and motion estimation approach. Comput Electr Eng. 2015; 46:471-86.

32. Huizing AR, Hamers JP, Gulpers MJ and Berger MP. A cluster-randomized trial of an educational intervention to reduce the use of physical restraints with psychogeriatric nursing home residents. J Am Geriatr Soc. 2009; 57:1139-48. | Article | PubMed

33. Chang W-Y, Chang K-W and Hsu Y-L. Using fractal dimension derived from trajectory measured by motion sensing carpet to assess wandering behaviors of dementia patients. 2015; 3:333-4. | Article

34. Kogure T, Shirakawa S, Shimokawa M and Hosokawa Y. Automatic sleep/ wake scoring from body motion in bed: validation of a newly developed sensor placed under a mattress. J Physiol Anthropol. 2011; 30:103-9. I Article I PubMed

35. Capezuti E, Brush BL, Lane S, Rabinowitz HU and Secic M. Bed-exit alarm effectiveness. Arch Gerontol Geriatr. 2009; 49:27-31. I Article I PubMed Abstract | PubMed FullText

36. Hsiao RS, Mi Z, Yang BR, Kau LJ, Bitew MA and Li TY. Body posture recognition and turning recording system for the care of bed bound patients. Technol Health Care. 2015; 24 Suppl 1:S307-12. | Article | PubMed

37. Chen D, Chang Y, Yan R and Yang J. Tools for Protecting the Privacy of Specific Individuals in Video. EURASIP J Adv Signal Process 2007; 2007:075427. | Article

38. Popescu M and Mahnot A. Early illness recognition using in-home monitoring sensors and multiple instance learning. Methods Inf Med. 2012; 51:359-67. | Article | PubMed

39. Tamrat T, Kachnowski S, Rupcic S, Griffin M, Taylor TT and Barfield J. 
Fehling et al. Journal of Nursing 2017,

Operationalizing a wireless wearable fall detection sensor for older adults. Proceedings of the 6th International Conference on Pervasive Computing Technologies for Healthcare. 2012. | Article

40. Pat Rapp M, Nelson F, Oliver M, Bergstrom N and Cron SG. Comparison of commonly used placement sites for activity monitoring. Biol Res Nurs. 2010; 11:302-9. | Article | PubMed

41. Kearns WD, Fozard JL, Becker M, Jasiewicz JM, Craighead JD, Holtsclaw L and Dion C. Path tortuosity in everyday movements of elderly persons increases fall prediction beyond knowledge of fall history, medication use, and standardized gait and balance assessments. J Am Med Dir Assoc. 2012; 13:665 e7-665 e13. | Article | PubMed

42. Donald F, Kilpatrick K, Reid K, Carter N, Bryant-Lukosius D, MartinMisener R, Kaasalainen S, Harbman P, Marshall D and DiCenso A. Hospital to community transitional care by nurse practitioners: a systematic review of cost-effectiveness. Int J Nurs Stud. 2015; 52:436-51. | Article | PubMed

43. Blomberg K, Griffiths $P$, Wengstrom $Y$, May $C$ and Bridges J. Interventions for compassionate nursing care: A systematic review. Int J Nurs Stud. 2016; 62:137-55. | Article | PubMed

44. Liu W, Galik E, Boltz M, Nahm ES and Resnick B. Optimizing Eating Performance for Older Adults With Dementia Living in Long-term Care: A Systematic Review. Worldviews Evid Based Nurs. 2015; 12:228-35. | Article I PubMed

45. Lindwedel-Reime U, Bejan A, Kirchhofer B and Koenig P. Evaluation and Outcomes of Assistive Technologies in an Outpatient Setting: A Technical-Nursing Science Approach. In: Kollak I, editor. Safe at Home with Assistive Technology, Springer International Publishing. 2017; 15371.

46. Coupland J. The granny: Public representations and creative performance. Pragmatics and Society. 2013; 4:82-104.

47. Domajnko B and Pahor M. Health Within Limitations: Qualitative Study of the Social Aspects of Resilience in Old Age. Ageing Int. 2015; 40:187200. | Article

48. Almeida ST, Soldera CL, Carli GA, Gomes I and Resende Tde L. Analysis of extrinsic and intrinsic factors that predispose elderly individuals to fall. Rev Assoc Med Bras (1992). 2012; 58:427-33. | Article | PubMed

49. Vieira ER, Freund-Heritage $R$ and da Costa BR. Risk factors for geriatric patient falls in rehabilitation hospital settings: a systematic review. Clin Rehabil. 2011; 25:788-99. | Article | PubMed

50. Mariano C. Holistic nursing: Scope and standards of practice. Holistic Nursing: A Handbook for Practice. 2013; 59-84.

51. Papathanasiou I. Holistic Nursing Care: Theories and Perspectives. AJNS. 2013; 2:1.

52. Bankole A, Anderson M, Knight A, Oh K, Smith-Jackson T and Hanson MA. Continuous, non-invasive assessment of agitation in dementia using inertial body sensors. Proceedings of the 2 nd Conference on Wireless Health - WH'11. 2011. | Article

53. Chen D, Bharusha A and Wactlar H. People Identification Across Ambient Camera Networks. Information Sciences. 2007; 2007:1503-9. | Article

54. Aud MA, Abbott CC, Tyrer HW, Neelgund RV, Shriniwar UG, Mohammed $A$ and Devarakonda KK. Smart Carpet: Developing a sensor system to detect falls and summon assistance. J Gerontol Nurs. 2010; 36:8-12. Article | PubMed

55. Drori GS. Science in the Modern World Polity: Institutionalization and Globalization. Stanford University Press. 2003.

56. Resnik DB and Elliott KC. The Ethical Challenges of Socially Responsible Science. Account Res. 2016; 23:31-46. | Article | PubMed Abstract | PubMed FullText

57. laccarino M. Science and ethics. As research and technology are changing society and the way we live, scientists can no longer claim that science is neutral but must consider the ethical and social aspects of their work. EMBO Rep. 2001; 2:747-50. | Article | PubMed Abstract | PubMed FullText

58. Yu S-I, Yang Y and Hauptmann A. Harry Potter's Marauder's Map:
Localizing and Tracking Multiple Persons-of-Interest by Nonnegative Discretization. 2013 IEEE Conference on Computer Vision and Pattern Recognition. 2013. | Article

59. Ozair FF, Jamshed N, Sharma A and Aggarwal P. Ethical issues in electronic health records: A general overview. Perspect Clin Res. 2015; 6:73-6. | Article | PubMed Abstract | PubMed FullText

60. Jit B, Maniyeri J, Louis S and Philip YL. Fast matching of sensor data with manual observations. Conf Proc IEEE Eng Med Biol Soc. 2009; 2009:16758. | Article | PubMed

61. Sifford KS and Bharucha A. Benefits and challenges of electronic surveillance in nursing home research. Res Gerontol Nurs. 2010; 3:5-10. | Article | PubMed

62. Niemeijer AR, Depla MF, Frederiks BJ and Hertogh CM. The experiences of people with dementia and intellectual disabilities with surveillance technologies in residential care. Nurs Ethics. 2015; 22:307-20. | Article | PubMed

63. Gietzelt M, Feldwieser F, Govercin M, Steinhagen-Thiessen E and Marschollek M. A prospective field study for sensor-based identification of fall risk in older people with dementia. Inform Health Soc Care. 2014; 39:249-61. | Article | PubMed

64. Braun SM, Kleynen M, Bleijlevens MH, Moser A, Beurskens AJ and Lexis MA. "Interactive surfaces" technology as a potential tool to stimulate physical activity in psychogeriatric nursing home residents. Disabil Rehabil Assist Technol. 2014. | Article | PubMed

65. Kallman U, Engstrom M, Bergstrand S, Ek AC, Fredrikson M, Lindberg $L G$ and Lindgren $M$. The effects of different lying positions on interface pressure, skin temperature, and tissue blood flow in nursing home residents. Biol Res Nurs. 2015; 17:142-51. | Article | PubMed

66. Kangas $M$, Vikman I, Wiklander J, Lindgren $P$, Nyberg L and Jamsa T. Sensitivity and specificity of fall detection in people aged $\mathbf{4 0}$ years and over. Gait Posture. 2009; 29:571-4. | Article | PubMed

67. Lipsitz LA, Tchalla AE, Iloputaife I, Gagnon M, Dole K, Su ZZ and Klickstein L. Evaluation of an Automated Falls Detection Device in Nursing Home Residents. J Am Geriatr Soc. 2016; 64:365-8. | Article | PubMed

68. Martien S, Delecluse C, Seghers J and Boen F. Counting Steps in Institutionalized Older Adults During Daily Life Activities: The Validation of Two Motion Sensors. J Aging Phys Act. 2015; 23:383-90. | Article | PubMed

69. Martien S, Seghers J, Boen F and Delecluse C. Energy Expenditure in Institutionalized Older Adults: Validation of SenseWear Mini. Med Sci Sports Exerc. 2015; 47:1265-71. | Article | PubMed

70. Merilahti J, Viramo P and Korhonen I. Wearable Monitoring of Physical Functioning and Disability Changes, Circadian Rhythms and Sleep Patterns in Nursing Home Residents. IEEE J Biomed Health Inform. 2016; 20:856-864. | Article | PubMed

71. Nakamoto $H$, Matsumoto $T$, Goka $M$, Kitagawa $Y$, Kameyama $H$ and Kamise $Y$ et al. Development of multi-camera gate for fall detection in nursing home with face-recognition. Gerontechnology. 2010; 9. | Article

72. Nava-Munoz $S$ and Moran AL. CANoE: a context-aware notification model to support the care of older adults in a nursing home. Sensors (Basel). 2012; 12:11477-504. | Article | PubMed Abstract | PubMed FullText

73. Zhu Y, Lan T, Yang Y, Robinovitch S and Mori G. Latent Spatio-temporal Models for Action Localization and Recognition in Nursing Home Surveillance Video. MVA. 2013; 463-466.

74. Perrochon A, Tchalla AE, Bonis J, Perucaud F and Mandigout S. Effects of a Multicomponent Exercise Program on Spatiotemporal Gait Parameters, Risk of Falling and Physical Activity in Dementia Patients. Dement Geriatr Cogn Dis Extra. 2015; 5:350-60. | Article | PubMed Abstract | PubMed FullText

75. Phillips LJ, Petroski GF and Markis NE. A Comparison of Accelerometer Accuracy in Older Adults. Res Gerontol Nurs. 2015; 8:213-9. | Article | PubMed

76. Rantz MJ, Skubic M and Miller SJ. Using sensor technology to augment 
Fehling et al. Journal of Nursing 2017,

http://www.hoajonline.com/journals/pdf/2056-9157-4-1.pdf

traditional healthcare. Conf Proc IEEE Eng Med Biol Soc. 2009;

2009:6159-62. | Article | PubMed

77. Rantz M, Lane K, Phillips LJ, Despins LA, Galambos C, Alexander GL, Koopman RJ, Hicks L, Skubic M and Miller SJ. Enhanced registered nurse care coordination with sensor technology: Impact on length of stay and cost in aging in place housing. Nurs Outlook. 2015; 63:650-5. | Article | PubMed

78. Guettari T, Boudy J, Istrate D, Benkhelfat BE, Baldinger JL and Doré P. A Multimodal Corpus Recorded in a Health nursing home. Stud. Inform. Univ. 2013; 11:88-102.

\section{Citation:}

Fehling P and Dassen T. A critical systematic review and synopsis of the alignment of scientific developments in surveillance technology in nursing care facilities. Journal of Nursing. 2016; 4:1.

http://www.hoajonline.com/nursing/2056-9157/4/1 